\title{
Investigation of Fuel Injector Tip Wetting Using Laser-induced Fluorescence under Flash Boiling Conditions
}

\author{
Shuyi Qiu', Di Xiao' ${ }^{1}$ Zhikai Zhao', Tianyun $\mathrm{Li}^{2}$, Jianye $\mathrm{Su}^{2}$, David Hung ${ }^{3}$, Xuesong Li ${ }^{\star 1}$, Min \\ $\mathrm{Xu}^{1}$ \\ ${ }^{1}$ School of Mechanical Engineering, Shanghai Jiao Tong University, 800 Dongchuan Road, \\ Shanghai, China 200240 \\ 2United Automotive Electronic Systems Co., Ltd.No. 555 Rong Qiao Road, Pudong New \\ Area, Shanghai, China 201206 \\ ${ }^{3}$ University of Michigan-Shanghai Jiao Tong University Joint Institute, Shanghai Jiao Tong \\ University,800 Dongchuan Road, Shanghai, China 200240 \\ *Corresponding author email: xuesonl@sjtu.edu.cn
}

\begin{abstract}
Tip wetting due to the needle descent and the rapid pressure drop in the nozzle has been identified as an important problem in gasoline direct injection (GDI) engines. The deposited film cannot fully evaporate before the onset of combustion and when the flame reaches the injector, high temperature and the lack of oxygen will lead to significant particulate emissions. Attempts have been made to reduce the tip wetting phenomenon by re-designing the nozzle geometry parameters. However, existing research is still limited to indirect measurements by analyzing the relationship between PN emissions and operating conditions and optical methods visualizing the results are fairly limited. Besides, flash boiling sprays have been considered a promising technology for GDI-related applications, but their performance on tip wetting remains controversial. Although it is expected that improvements in vaporization could reduce the deposition, research also shows that the spray-tip interaction could be enhanced by excessive plume width. To clarify the underlying mechanism, investigations of tip wetting phenomena under flash boiling conditions were conducted in a constant volume chamber by controlling the ambient pressure and fuel temperature. Laser-induced fluorescence (LIF) method was adopted and $266 \mathrm{~nm} \mathrm{Nd}$ : YAG laser was used to excite the commercial gasoline. The intensified CCD camera equipped with a microscope lens was applied to capture the fluorescence. The characteristics of tip wetting (film area and time-resolved evolution) were thoroughly analyzed, and the influence of flash boiling on tip wetting was evaluated.
\end{abstract}

Keywords: Direct gasoline injection; tip wetting; Laser-induced Fluorescence (LIF); flash boiling

Subject area: Liquid drops and Interfaces 
ICLASS 2021, 15 th Triennial International Conference on Liquid Atomization and Spray Systems, Edinburgh, UK, 29 Aug. - 2 Sept. 2021 


\section{Introduction}

Spray atomization has been one of the key elements in hydrocarbon fuel energy conversions, such as for vehicle powertrain applications and gas turbine applications. With the surge of vehicle electrification and the need for carbon emission reduction in the automotive field, surprisingly, the atomization of hydrocarbon fuels attracts even more attention and efforts from researchers and industrials. With increasingly stringent regulations on vehicle emissions, very detailed investigations are required for automakers rather than the purpose of just injecting the fuel into the combustion chamber. For instance, besides investigations on the macroscopic morphology of the fuel spray and corresponding fuel-air mixing in the combustion cylinder, the liquid-solid coupling process during spray atomization is also critical in determining combustion soot emission since combustion on the liquid surface (pool fire) is not desired.

Typical liquid-solid interactions during spray atomization in internal combustion (IC) engines include spray wall impingement and tip wetting phenomenon. Usually, researchers would invest more effort in reducing spray impingement onto the cylinder wall or engine piston. Methods such as multiple injection strategies or active fuel heating (flash boiling) can help relieve this issue, besides modifying fuel injector designs with regards to combustion cylinder design. However, recently, tip wetting gains more research interests in both fundamental and practical aspects. One of the reasons for this interest is that as spray wall impingement is suppressed, the relatively small amount of soot formation at the injector tip may dominate or take up a large portion in the end PN emission. There are many explanations about the mechanisms of tip wetting. For instance, it is held that tip wetting is mainly contributed by three factors: (1) Fuel impingement on the edge of the pre-hole, (2) vortex tip wetting, and (3) fuel dribble/dripping [1]. The first factor is mainly the results of overly expanding spray plumes impinging onto the wall of step holes. The second issue is primarily associated with strong spray entrainment motions near the injector tip (for instance, under flash boiling conditions). In this scenario, fuel droplets might be carried by the airflow and then impinge onto the injector tip. The third issue is related to the valve closing process at the end of the fuel injection. As the needle valve closes, the exiting velocity of the fuel suddenly drops, which would deteriorate spray atomization. Furthermore, the fuel deposits inside the step hole might be brought out to the tip surface by the fuel flow near the end of injection, which is the so-called fuel dripping. Although three likely reasons have been demonstrated, it is still not clear which process dominates under various injection conditions.

Flash boiling atomization, as we mentioned previously, is a promising technique in promoting spray atomization performance with the assistance of fuel active heating [2-5]. With a high fuel temperature and/or a low ambient pressure, as the local saturated vapor pressure of the fuel grows higher than the local pressure, the liquid fuel would vaporize even inside the nozzle. Such physics would lead to micro-explosion in the near field of the fuel injector, which would enhance the atomization efficiency and possibly switch the primary breakup mechanisms of the fuel atomization. There have been many flash boiling-related fuel spray analyses both in constant volume chambers and optical engine facilities. It has been demonstrated that flash boiling atomization can remarkably reduce wall impingement (and thus soot emissions, improve thermal efficiency, and reduce cycle-to-cycle variation [6-9], the combustion near the injector tip is still rich, and yellow sooty flames were spotted [10, 11]. However, Leick et al. [12] studied tip wetting characteristics using laser-induced fluorescence, combined with side-view microscopic measurements. They showed that the tip wetting film area under flash boiling 
conditions was notably greater than that under sub-cooled conditions. They stated that flash boiling and injection pressure could significantly impact the tip wetting phenomena, but they didn't specify which mechanism contributed the most to the formation of tip wetting film formation. Similar observations were also found by Park et al. [13]. However, the studies are still preliminary and were not systematically explored. In this work, we are not intended to perform such a thorough investigation; rather, we will explore another flash boiling-related tip wetting case with a different setting comparing with Leick et al., and we hope that the results of this current study would inspire theories/ mechanisms regarding the formation of tip wetting fuel film.

\section{Material and Methods}

The experimental setup is incorporated in Figure 1. In this work, we adopted an experimental setup similar to that in Leick et al. [12]. The fuel injector used in this work is a two-hole injector mounted at the side of a constant volume chamber, with the schematic of the injection shown in Figure 2. The ambient pressure is controlled by external nitrogen sources and a vacuum pump. The ambient temperature is controlled by an internal heating element and a PID control system to keep the vessel temperature within a narrow range (usually $\pm 1.0^{\circ} \mathrm{C}$ ). The fuel used in this work is commercial gasoline to simulate practical applications. Since commercial gasoline can trigger laser-induced fluorescence, no additional tracer was doped into the fuel. The tip film was then illuminated by a $10 \mathrm{~Hz} \mathrm{Nd}$ : YAG laser operated at its fourth harmonic $(266 \mathrm{~nm})$, with a laser pulse energy of $\sim 50 \mathrm{~mJ}$ monitored by a laser power meter. The laser beam was directed into the chamber via a reflection mirror and a dichroic filter, then hit the injector tip after fuel injection. The resultant laser-induced fluorescence signal propagates back and through the dichroic filter into the imaging system. No filter was used in this study, and inelastic scattering light in the wavelength of $266 \mathrm{~nm}$ was blocked by the regular lens of the microscope. Then an intensified CCD (ICCD) camera was used to collect the fluorescence signal in a width spectrum to enhance the signal.

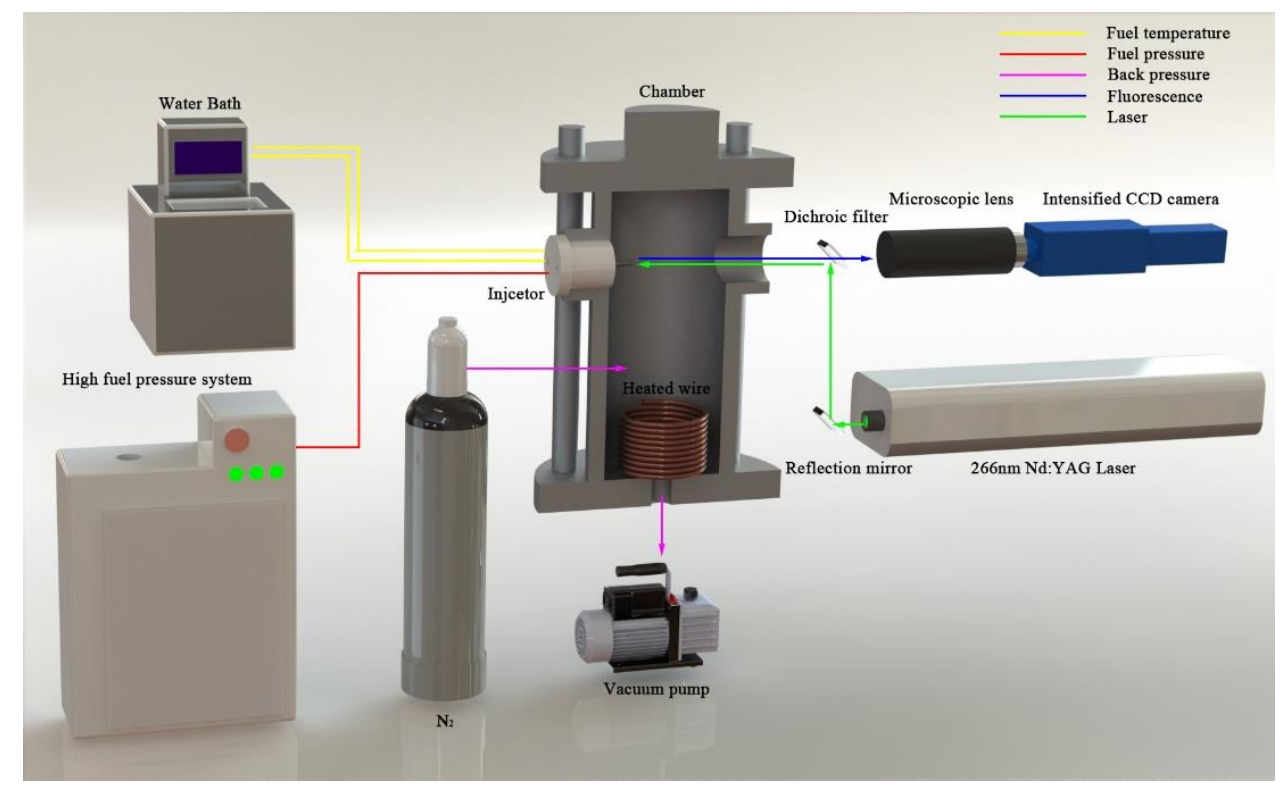

Figure 1. Experimental setup for the Tip Wetting experiments. 


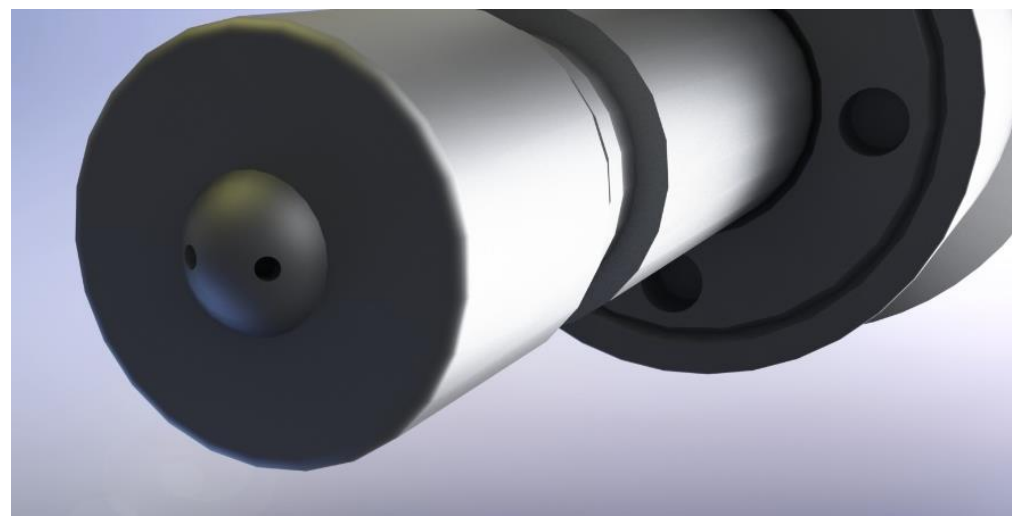

Figure 2. Schematic of the two-hole injector used in this study.

The experiment conditions in this work are summarized in Table 1. As can be seen, we chose three fuel temperature conditions, including $25^{\circ} \mathrm{C}, 55^{\circ} \mathrm{C}$, and $90^{\circ} \mathrm{C}$, respectively. The temperature of $25^{\circ} \mathrm{C}$ represents sub-cooled fuel injection conditions, the temperature of $55^{\circ} \mathrm{C}$ represents mild flash boiling conditions (transition flash boiling), under which some light components will experience flash boiling processes, and finally, $90^{\circ} \mathrm{C}$ more pronounced flash boiling processes (sort of flare flash boiling). The injection pressure was $35 \mathrm{MPa}$, and the injection duration was set to $1.5 \mathrm{~ms}$, which reflects the recent advances of the commercial gasoline powertrains. A time-resolved measurement was implemented, and we chose 4, 5, 7, $10,15,20,50 \mathrm{~ms}$ after start of injection (ASOI) to study the evolvement of tip wetting films. It should be noted that the results were from individual tests and were not taken in a sequential manner since the laser frequency was only $10 \mathrm{~Hz}$. 15 shots were made under each timing and condition.

Table 1 - Conditions used in this study.

\begin{tabular}{cccccc}
\hline $\begin{array}{c}\text { Operating } \\
\text { point }\end{array}$ & $\mathrm{T}_{\text {fuel }}\left[{ }^{\circ} \mathrm{C}\right]$ & $\begin{array}{c}\mathrm{P}_{\text {fuel }} \\
{[\mathrm{Mpa}]}\end{array}$ & $\begin{array}{c}\mathrm{P}_{\text {amb }} \\
{[\mathrm{bar}]}\end{array}$ & $\begin{array}{c}\text { Pulse width } \\
{[\mathrm{ms}]}\end{array}$ & $\begin{array}{c}\text { Time } \\
{[\mathrm{ms} \mathrm{ASOI}]}\end{array}$ \\
\hline 1 & 25 & 35 & 0.4 & 1.5 & $4,5,7,10,15,20,50$ \\
2 & 55 & 35 & 0.4 & 1.5 & $4,5,7,10,15,20,50$ \\
3 & 90 & 35 & 0.4 & 1.5 & $4,5,7,10,15,20,50$ \\
\hline
\end{tabular}

\section{Results and Discussion}

In this section, we first exhibit the tip wetting wall film results from LIF measurements at different timings, respectively. As discussed, data from 15 cycles were obtained for this specific two-hole fuel injector, and in Figure 3, we selected representative film measurements for comparison and discussion. The results shown in Fig. 3 are all processed LIF measurements results, displayed in pseudo-color, and the brightness is used to characterize the fluorescence intensity. After we get the Raw data, we will 1) subtract the background image (to eliminate the effect of background noise); 2) crop the fluorescence from the nozzle holes (exclude the impact of residual fuel within the step holes); and 3) eliminate pixels that are too weak (Less than $5 \%$ of the maximum intensity, which is considered to be the boundary of the fuel film). As seen, as the fuel temperature was low (at $25^{\circ} \mathrm{C}$ ), the film thickness distribution (represented by LIF intensity) was relatively discrete (at early injection timings). The film become thinner as time elapsed, but the film area grew as the film spread on the injector tip. 
Under the fuel temperature of $55^{\circ} \mathrm{C}$ (transitional flash boiling), the film area was notably larger than that under $25^{\circ} \mathrm{C}$ fuel injections. Overall, the film thickness appears to be thinner than $25^{\circ} \mathrm{C}$ fuel injections. Such observations are in agreement with the results shown in Leick et al. [12]. However, under a $90^{\circ} \mathrm{C}$ fuel injection temperature, the tip wetting performance was again comparable to that under a $25^{\circ} \mathrm{C}$ fuel injection temperature. At early injection timings, the tip film thickness of $90^{\circ} \mathrm{C}$ injections was smaller than that under $25^{\circ} \mathrm{C}$. As time elapsed, the tip film intensity dropped (due to evaporation), and the film was not significant at $50 \mathrm{~ms}$ ASOI. These observations contradict the conclusions in Leick et al. [12] that flash boiling would usually deteriorate tip wetting performance. While these observations actually make sense that flash boiling would firstly increase tip film deposition and then decrease tip film formation because of very strong evaporation/ boiling. Imagining further increasing the fuel temperature to super-critical states, then no liquid phase would inject into the ambient, and theoretically, there would be no tip film at all, given no condensation takes place. In our opinion, the amount of tip film under flash boiling conditions is determined by the completion of film deposit onto the tip and the speed of evaporation. It is indicated in the results that the film can evaporate fast enough (even at $4 \mathrm{~ms}$ ASOI) to offset the disadvantages induced by high-temperature fuels (with a lower viscosity).

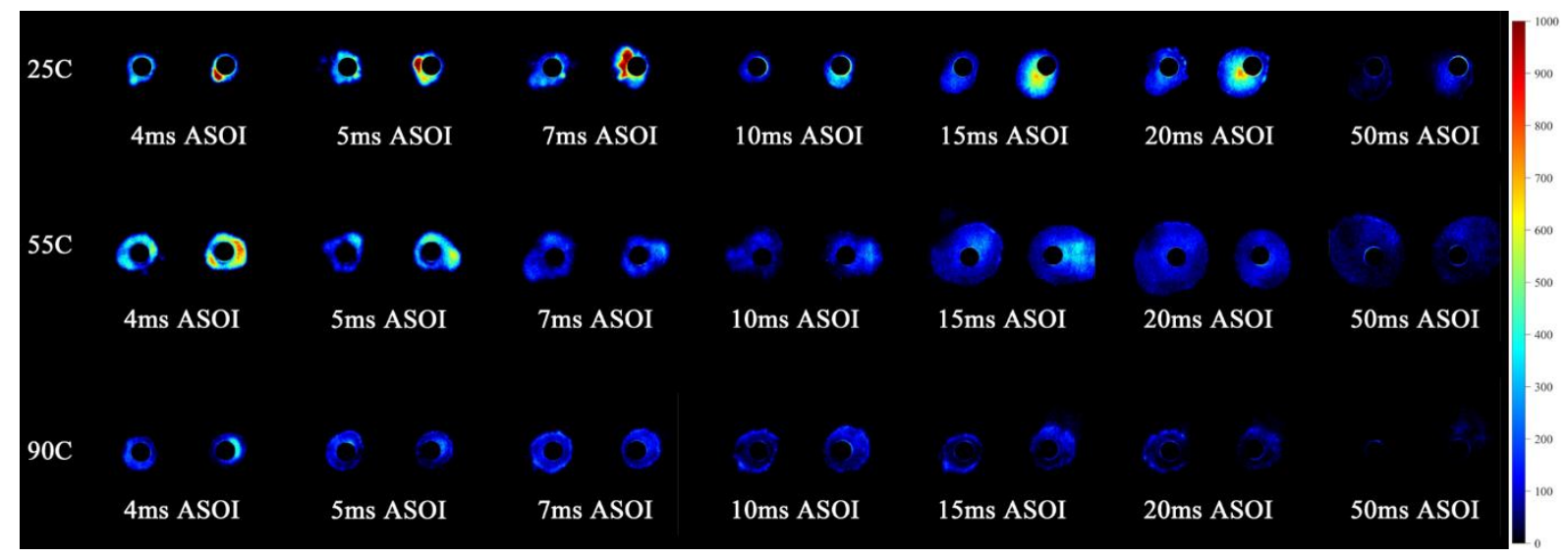

Figure 3. Representative film distribution under different conditions.

Figure 4 compares the tip film area as a function of ASOI under different conditions. The results from 15 cycles were summarized, and the mean+std data were plotted in Figure 4. The integrated fluorescence of the tip film results are shown in Figure 5 in a similar manner. The statistical results were generally in agreement with the measurements shown in Figure 3 . It can be found that under $55^{\circ} \mathrm{C}$ injection conditions, the magnitude and fluctuation of tip film were both more pronounced compared with $25^{\circ} \mathrm{C}$ and $90^{\circ} \mathrm{C}$ injection conditions. The film area under $55^{\circ} \mathrm{C}$ conditions was positively correlated to ASOI before $50 \mathrm{~ms}$, and the area remained a close value from $20 \mathrm{~ms}$ to $50 \mathrm{~ms}$ ASOI. In addition, the fluorescence intensity under $55^{\circ} \mathrm{C}$ gradually dropped as the time elapsed. Such results reflect that the evaporation rate of the film under $55^{\circ} \mathrm{C}$ conditions is also strong, but the film has spread sufficiently large before effective evaporation. Therefore, a large and thin film is the result under this specific condition, which is not desirable for combustion-related application since the film area is a crucial parameter in evaluating pool fire tendency.

As for $90^{\circ} \mathrm{C}$ conditions, during the injection timing from $5 \mathrm{~ms}$ to $15 \mathrm{~ms}$ ASOI, the fluorescence intensity is lower than that under $25^{\circ} \mathrm{C}$, but the film area is larger. Such observations indicate that the dissipation of the film under $90^{\circ} \mathrm{C}$ is more significant due to a lower fuel viscosity. 
Meanwhile, the film area under $90^{\circ} \mathrm{C}$ dropped remarkably after $20 \mathrm{~ms}$ ASOI, which reflects fast evaporation due to high temperature. Finally, it is worth noting that for $25^{\circ} \mathrm{C}$ only, we have witnessed some increase in fluorescence intensity as time elapsed. This observation indicates the fuel trapped in the step hole escaped notably under sub-cooled injection conditions.

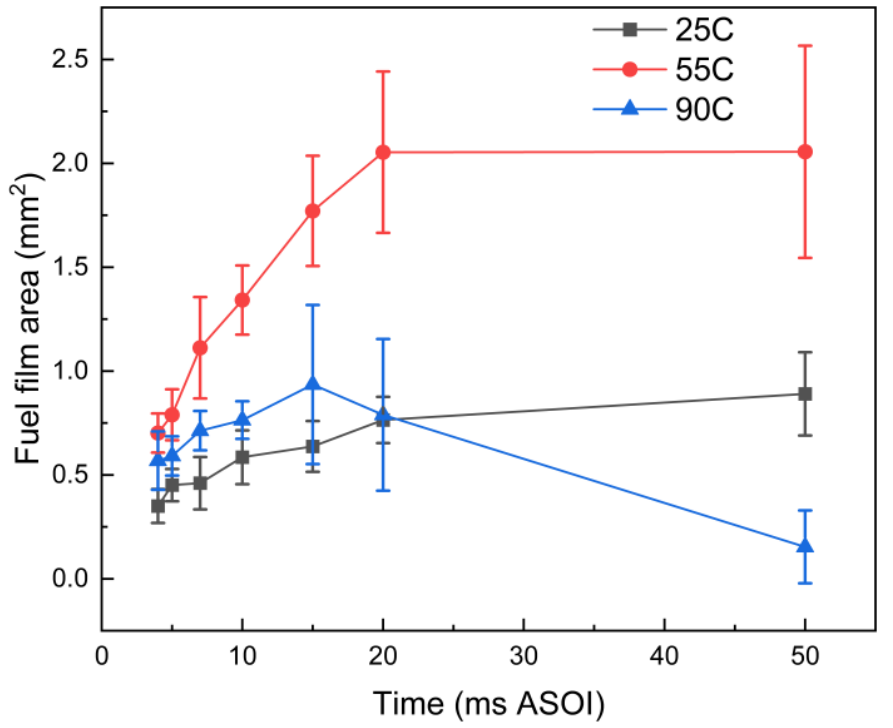

Figure 4. Fuel film area as a function of time (AOSI).

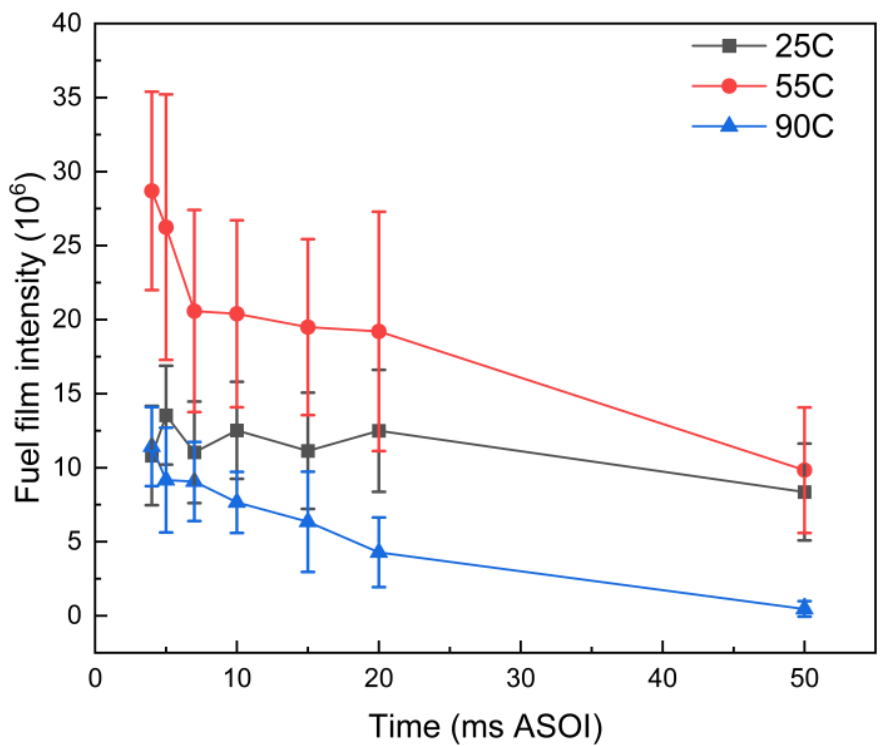

Figure 5. Fuel film integrated intensity (representing film mass) as a function of time (AOSI).

Lastly, we quantitatively evaluate the fuel film characteristics, and the results are incorporated in Table 2. We define the evaporation rate as the maximum intensity integrated minus the minimum intensity integrated, then divided by the maximum intensity integrated. It is seen that the evaporation rate increases monotonously as the fuel temperature increases. Furthermore, the maximum intensity time under $25^{\circ} \mathrm{C}$ was $5 \mathrm{~ms}$ ASOI, which reflects again that notable fuel had escaped from the step hole and form a part of the tip film. 
Table 2 - Statistics from tip film measurements

\begin{tabular}{cccccc}
\hline $\begin{array}{c}\text { Fuel } \\
\begin{array}{c}\text { Temperature } \\
{\left[{ }^{\circ} \mathrm{C}\right]}\end{array}\end{array}$ & $\begin{array}{c}\text { Maximum } \\
\text { intensity time } \\
{[\mathrm{ms} \mathrm{ASOI}]}\end{array}$ & $\begin{array}{c}\text { Maximum } \\
\text { intensity } \\
{\left[{ }^{*} 10^{\wedge} 6\right]}\end{array}$ & $\begin{array}{c}\text { Minimum } \\
\text { intensity time } \\
{[\mathrm{ms} \text { ASOI] }}\end{array}$ & $\begin{array}{c}\text { Minimum } \\
\text { intensity } \\
{\left[{ }^{*} 10^{\wedge} 6\right]}\end{array}$ & $\begin{array}{c}\text { Evaporation } \\
\text { rate } \\
{[\%]}\end{array}$ \\
\hline 25 & 5 & 13.54813 & 50 & 8.35915 & 38.30 \\
55 & 4 & 35 & 50 & 9.83491 & 65.73 \\
90 & 4 & 35 & 50 & 0.46156 & 95.96 \\
\hline
\end{tabular}

\section{Conclusions}

In this study, we investigated the tip wetting phenomena with different fuel temperatures using a two-hole injector. Part of our results was in alignment with previous studies, and part of the results have not been established by other studies. The following conclusions are drawn:

1. As the flash boiling level is medium (transitional flash boiling), the tip wetting performance was the worst; while as the flash boiling level is further elevated, the film deposited on the tip reduced both in size and mass.

2. There is a trade-off between the viscosity of fuel affected by temperature (which impacts the leaking of fuel during the valve closing phase) and the evaporation tendency affected by temperature. Therefore, to minimize the tip film formation, it is recommended that the transitional flash boiling phase is avoided in practical applications.

3. With regard to the aspects of engine application, it is crucial to match the tip film generation timing and engine spark timing. For instance, although the tip film evaporation could be fast under flash boiling conditions, it is likely that the spark timing is more advanced before the film completely evaporates. Furthermore, as the engine is fully operational, the temperature of the cooling water can reach $\sim 80-90^{\circ} \mathrm{C}$, at which temperature the evaporation is pronounced. However, during warm engine conditions, the fuel is heated to only transitional flash boiling regimes. Therefore it is expected that tip-wetting-induced pool fire contributes more notably under this condition.

\section{Acknowledgments}

The authors would like to acknowledge the financial support and technical contribution to this project from United Automotive Electronic Systems Co., Ltd. This research was also sponsored by the National Natural Science Foundation of China (NSFC) under Grants No. E52006140 and No. E51876126. The study was carried out at the National Engineering Laboratory for Automotive Electronic Control Technology of Shanghai Jiao Tong University.

\section{References}

1. Medina, M., F. Alzahrani, M. Fatouraie, M. Wooldridge, and V. Sick, Mechanisms of fuel injector tip wetting and tip drying based on experimental measurements of engineout particulate emissions from gasoline direct-injection engines. International Journal of Engine Research. 0(0): p. 1468087420916052.

2. Yang, S., Z. Ma, X. Li, D.L.S. Hung, and M. Xu, A review on the experimental nonintrusive investigation of fuel injector phase changing flow. Fuel, 2020. 259: p. 116188. 
3. Yang, S., X. Li, D.L. Hung, M. Arai, and M. Xu, In-nozzle flash boiling flow of multicomponent fuel and its effect on near-nozzle spray. Fuel, 2019. 252: p. 55-67.

4. Guo, H., B. Wang, Y. Li, H. Xu, and Z. Wu, Characterizing external flashing jet from single-hole GDI injector. International Journal of Heat and Mass Transfer, 2018. 121: p. 924-932.

5. Xu, Q., H. Pan, Y. Gao, X. Li, and M. Xu, Investigation of two-hole flash-boiling plumeto-plume interaction and its impact on spray collapse. International Journal of Heat and Mass Transfer, 2019. 138: p. 608-619.

6. Nour, M., Z. Sun, M. Cui, D. Hung, X. Li, and M. Xu, Effect of flash boiling injection on combustion and PN emissions of DISI optical engine fueled with butanol isomers/TPRF blends. Proceedings of the Combustion Institute, 2021.

7. Ye, C., Z. Sun, M. Cui, X. Li, D. Hung, and M. Xu, Ultra-lean Limit Extension for Gasoline Direct Injection Engine Application via Flash Boiling Atomization. Proceedings of the Combustion Institute, 2021.

8. Sun, Z., M. Cui, C. Ye, S. Yang, X. Li, D. Hung, and M. Xu, Split Injection Flash Boiling Spray for high efficiency and low emissions in a GDI Engine under Lean Combustion Condition. Proceedings of the Combustion Institute, 2021.

9. Xiao, D., S. Qiu, D. Hung, X. Li, K. Nishida, and M. Xu, Evaporation and condensation of flash boiling sprays impinging on a cold surface. Fuel, 2021. 287: p. 119423.

10. Sun, Z., M. Cui, M. Nour, X. Li, D. Hung, and M. Xu, Study of flash boiling combustion with different fuel injection timings in an optical engine using digital image processing diagnostics. Fuel, 2021. 284: p. 119078.

11. Sun, Z., S. Yang, M. Nour, X. Li, D. Hung, and M. Xu, Significant Impact of Flash Boiling Spray on In-Cylinder Soot Formation and Oxidation Process. Energy \& Fuels, 2020. 34(8): p. 10030-10038.

12. Leick, P., B. Bork, and J.N. Geiler. Experimental characterization of tip wetting in gasoline DI injectors. in ICLASS 2018, 14th Triennial International Conference on Liquid Atomization and Spray Systems. 2018. Chicago, IL, US.

13. Park, C., J. Jung, C. Bae, H. Oh, and J. Lee. Injector tip wetting visualization under flash-boiling and non-flash boiling conditions. in ILASS-Korea 2018. 2018. 